\title{
The Pattern of Eosinophil Count among Nigerians with Frequent Use of the Commonly Available Non-Steroidal Anti-Inflammatory Drugs (NSAIDs)
}

\author{
P. K. Uduagbamen ${ }^{1,2}$, A. T. Oyelese ${ }^{3}$, A. O. Adebola Yusuf ${ }^{4}$, O. F. Salami' ${ }^{5}$ C. M. Nwinee ${ }^{1}$, \\ M. I. Ogunmola1, 0. Ehioghae ${ }^{1}$
}

${ }^{1}$ Division of Nephrology and Hypertension, Department of Internal Medicine, Ben Carson School of Medicine, Babcock University/Babcock University Teaching Hospital, Ilishan-Remo, Nigeria

${ }^{2}$ Nephrology Unit, Department of Internal Medicine, Federal Medical Centre, Abeokuta, Nigeria

${ }^{3}$ Department of Haematology and Blood Transfusion, Ben Carson School of Medicine Babcock University/Babcock University Teaching Hospital, Ilishan-Remo, Nigeria

${ }^{4}$ Division of Radiology, Department of Surgery, Ben Carson School of Medicine Babcock University/Babcock University Teaching Hospital, Ilishan-Remo, Nigeria

${ }^{5}$ Intensive Care Unit, Department of Surgery, Ben Carson (Snr) School of Medicine, Babcock University/Babcock University Teaching Hospital, Ilishan-Remo, Nigeria

Email: ^petr.uduagbamen@gmail.com, oyelesea@babcock.edu.ng, adebolaolukayodeyusuf@gmail.com, tsalami40gmail.com, attahcherilyn@gmail.com,itmariodigie@yahoo.com,dr_ziggszz@yahoo.com

How to cite this paper: Uduagbamen, P.K., Oyelese, A.T., Adebola Yusuf, A.O., Salami, O.F., Nwinee, C.M., Ogunmola, M.I. and Ehioghae, O. (2020) The Pattern of Eosinophil Count among Nigerians with Frequent Use of the Commonly Available Non-Steroidal Anti-Inflammatory Drugs (NSAIDs). International Journal of Clinical Medicine, 11, 605-617.

https://doi.org/10.4236/ijcm.2020.1110051

Received: September 25, 2020

Accepted: October 25, 2020

Published: October 28, 2020

Copyright $\odot 2020$ by author(s) and Scientific Research Publishing Inc. This work is licensed under the Creative Commons Attribution International License (CC BY 4.0).

http://creativecommons.org/licenses/by/4.0/

\begin{abstract}
Introduction: Non-steroidal anti-inflammatory drugs (NSAIDs) use is very common. NSAIDs use could be associated with elevated eosinophil count which could be a class effect or patient-related. Inflammation could be the link between NSAIDs use and eosinophilia. Aims: To compare the pattern of eosinophil count in the peripheral blood of frequent users of NSAIDs and healthy controls. Methodology: Two hundred (one hundred frequent users of NSAIDs and 100 healthy controls) participants who had no known risk factor for kidney disease and had given informed consent were recruited. Blood was taken to determine the white cell count and differentials, serum electrolyte and creatinine, and random blood sugar. Results: The mean age of NSAIDs users was not significantly different from controls, $\mathrm{P}=0.3$. The mean eosinophil count was higher in males than females. The incidence of eosinophilia in NSAIDs users was $4 \%$. The mean Eosinophil count of NSAIDs users was insignificantly higher than controls, $164.3 \pm 516$ vs $135.6 \pm 53.4, \mathrm{P}$ $=0.4$. The mean platelet count of NSAIDs users was significantly higher compared to controls, $\mathrm{P}=0.04$. The mean hematocrit of NSAIDs users was significantly lower than the controls, $\mathrm{P}=0.02$. Propionic acid derivatives were
\end{abstract}


associated with the highest eosinophil count. Eosinophil count was positively related to age and serum creatinine and inversely related to blood glucose, hematocrit and glomerular filtration rate. Conclusion: The incidence of eosinophilia was $4 \%$. The eosinophil count was higher in frequent NSAIDs users than occasional and non-users, in males than females and with use propionic acid derivatives compared to other NSAIDs. The Eosinophil count was positively related to age and platelet count. Being commoner in inflammatory states, the tissue destruction associated with elevated EC can be avoided by the prevention and prompt treatment of inflammatory conditions.

\section{Keywords}

Eosinophilia, Kidney Function, Non-Steroidal Anti-Inflammatory Drugs, Hematocrit, Platelet Count, Propionic Acid

\section{Introduction}

Non-steroidal anti-inflammatory drugs (NSAIDs) are cheap and readily available agents used in treating pain [1]. NSAIDs use is very common in low-income nations like Nigeria, where there are significantly larger population of manual laborers and artisans due to the very low level of industrial mechanization compared to the developed countries [2]. NSAIDs use in treating rheumatic conditions is quite common in the elderly [3].

At the community level, Agaba et al. reported a $13 \%$ prevalence rate of NSAIDs use [2]. Twenty nine million Americans (12.1\%) were reported to be regular users of NSAIDs in 2010 [4]. Zeinali et al. also reported a high prevalence of NSAIDs use among Iranian with $19.3 \%$ of all prescriptions having at least, an NSAID and 7\% of these being combination NSAIDs [5].

NSAIDs use has been reported to be associated with eosinophilia and tissue eosinophilic infiltration [6]. These drugs inhibit cyclooxygenase (COX) pathway thereby inhibiting the release and actions of prostaglandins (PGs) which are made up of the following subunits: $\mathrm{PGD}_{2}, \mathrm{PGI}_{2}, \mathrm{PGE}_{2}$ and $\mathrm{PGF}_{2}$ [7]. Eosinophilia, with its chemo attractant actions, is mediated through NSAIDs effect on its $\mathrm{PGD}_{2}$ subunit [8]. Eosinophilia mediates airway remodeling and induces disease progression resulting in fibrosis of chronically inflamed cells that involves angiogenesis [9]. It is not known if the actions of NSAIDs on leucocytes are class effects or not as only Indomethacin has been reported to exhibit these features [8] [10] [11]. The relationship between NSAIDs use and inflammatory tissue damage, through the degranulation and release of cytopathic eosinophils and basophils has been reported from studies in the western world [12] [13]. Ironically, in sub-Sahara Africa and other low-income countries where NSAIDs use is commoner, the relationship between NSAIDs use and the pattern of eosinophil distribution is rarely reported. In this study, we determined the pattern of eosinophil distribution among Nigerians with frequent NSAIDs use, defined as daily use for up to a month [14]. 


\section{Methods}

A prospective, comparative study carried out at the Federal Medical Centre, Abeokuta, Nigeria, from January 2016 to December 2016, in which, two hundred (one hundred frequent NSAIDs users and 100 age and sex-matched healthy controls), eighteen years and above who gave consent were consecutively recruited. Ninety-two NSAIDs users were recruited from the orthopedic clinics and eight from among manual laborers/artisans working within and around the hospital construction sites. The controls were recruited from healthy hospital staffs and the surrounding community. Participants less than 18 years, with hypertension, diabetes, sickle cell anemia, diseases of the kidneys, heart or liver or risk factors for these diseases were excluded. Also excluded were participants who sneeze a lot, or had recurrent stuffy or running nose, watery eye, tight chest or itching on exposure to strong smell (perfumes, boiling oil or fumes), sandy air or to any food or drink and any other form of allergy. Participants with infection, hypertension, diabetes and proteinuria were also excluded.

Socio-demographics and drug history were obtained through an interviewer-administered questionnaire and from participants' case files. The NSAIDs users were shown packets, sachets and containers of the commonly used NSAIDs in the locality to ascertain those used by them, alone or in combination. Participants were described as frequent NSAIDs users when they take at least a unit (tablet, capsule, patch, ointment or suppository) daily for at least 1 month [14]. All participants had stool microscopy, culture and sensitivity for ova and parasite, prior to sample collection.

Participants' height and weight were measured without shoes and on very light clothing using a SECA standiometer and weighing scale respectively, and the body mass index (BMI) was calculated. Participants' pulse rate and blood pressure were taken after 5 minutes rest. Five milliliters of blood was taken from each participant into an ethlenediamine tetraacetic acid (EDTA) containing bottle, blood was mixed gently and immediately taken to the laboratory to determine the full blood count (FBC) including the total white cell count (WBC) and differentials including the eosinophil using the counting chamber. Another $3 \mathrm{ml}$ was taken for determination of serum electrolytes, urea and creatinine and the estimated glomerular filtration rate (eGFR) was calculated.

Definitions

Frequent NSAIDs use-daily use of at least a unit for $\geq 1$ month [14].

Eosinophilia-peripheral blood eosinophil count of $\geq 450 \times 10^{6} / 1$ [15].

Hypereosinophilia->1500 × 106/1 [16].

Kidney dysfunction-eGFR $<60 \mathrm{ml} / \mathrm{min}$ [17].

Anemia-hematocrit <39\% [18].

Sample size was calculated from the formula on comparative study using a previous study's prevalence [19].

Statistical analysis

Continuous variables were presented as mean with standard deviation and 
compared using student's t-test while categorical variables were presented as proportions and compared using chi-square or Fisher's exact test. Pearson correlation test was performed to determine the degree of correlation between eosinophil count and participants' characteristics. The level of $\mathrm{P}<0.05$ was considered statistically significant.

Ethical issues

The research followed the tenets of the Declaration of Helsinki. The Ethics Committee of the Federal Medical Centre, Abeokuta approved the study. The institutional ethical committee of the Federal Medical Centre approved all study protocols ((FMCA/238/HREC/09/2015). Accordingly, written informed consent was taken from all participants before any intervention

\section{Results}

Two hundred participants (100 frequent NSAIDs users and 100 age and sex-matched healthy controls) were recruited for the study. Forty-nine males and fifty-one females in each group participated. The mean age of the NSAIDs users and controls were $46.5 \pm 14.2$ and $46.2 \pm 14.3$ respectively, $\mathrm{P}=0.3$. There was no significant difference between the age, sex and diastolic BP of the NSAIDs users and the controls, $\mathrm{P}=0.5, \mathrm{P}=0.3, \mathrm{P}=0.6$ respectively. The demographic and clinical characteristics of the participants are shown in Table 1 . The mean BMI and systolic BP of the NSAIDs users were significantly higher than those of the controls, $\mathrm{P}=0.03$ and $\mathrm{P}<0.001$ respectively.

Table 1. Socio-demographic and clinical characteristics of participants.

\begin{tabular}{|c|c|c|c|c|c|}
\hline & \multirow{3}{*}{ Variables } & \multirow{2}{*}{$\begin{array}{l}\text { NSAIDs users } \\
\mathrm{N}=100(\%)\end{array}$} & \multirow{2}{*}{$\begin{array}{l}\text { NSAIDs users } \\
\mathrm{N}=100(\%)\end{array}$} & \multirow[t]{2}{*}{$\mathrm{X}^{2}$} & \multirow{3}{*}{ P-value } \\
\hline & & & & & \\
\hline & & Mean \pm SD & Mean \pm SD & t-test & \\
\hline \multirow[t]{2}{*}{ Gender } & Males & $49(49)$ & $49(49)$ & 0.55 & 0.5 \\
\hline & Females & $51(51)$ & $51(51)$ & & \\
\hline \multirow[t]{3}{*}{ Age, years } & $18-39$ & $28(28)$ & $34(34)$ & 0.70 & 0.3 \\
\hline & $40-59$ & $53(53)$ & $49(49)$ & & \\
\hline & $>60$ & 19 (19) & $17(17)$ & & \\
\hline WHR & & $1.0 \pm 0.1$ & $1.0 \pm 0.04$ & 0.01 & 0.8 \\
\hline Mean Age, years & & $46.5 \pm 14.2$ & $46.2 \pm 14.3$ & 0.3 & 0.3 . \\
\hline Mean BMI, $\mathrm{kg} / \mathrm{m}^{2}$ & & $28.1 \pm 13.1$ & $26.4 \pm 13.2$ & 3.04 & 0.03 \\
\hline Mean SBP, $m m H g$ & & $123.5 \pm 10.4$ & $114.0 \pm 1.2$ & 5.92 & $<0.001$ \\
\hline Mean DBP, $m m H g$ & & $75.7 \pm 8.2$ & $74.5 \pm 7.2$ & 0.03 & 0.6 \\
\hline
\end{tabular}

NSAIDs = non-steroidal anti-inflammatory drugs, $\mathrm{SD}=$ standard deviation, WHR-waist hip ratio, $\mathrm{BMI}=$ body mass index, $\mathrm{SBP}=$ systolic blood pressure, $\mathrm{DBP}=$ diastolic blood pressure, $\mathrm{S}=$ serum, eGFR = estimated glomerular filtration rate, CKD-EPI = chronic kidney disease epidemiology collaboration. 
Four (4) NSAIDs users had eosinophilia as against none among the controls. None of the participants had hypereosinophilia nor leukocytosis. Table 2 shows the laboratory results of the participants. There was no significant difference between the mean white cell count and eosinophil count of the NSAIDs users and the controls, $\mathrm{P}=0.1$ and $\mathrm{P}=0.4$ respectively. There was a significant difference between the platelet count and the hematocrit of the NSAIDs users and the controls, $\mathrm{P}=0.04$ and $\mathrm{P}=0.02$ respectively. There was a significant difference between the serum creatinine and glomerular filtration rate of NSAIDs users and the controls, $\mathrm{P}<0.001$ and $\mathrm{P}<0.001$ respectively.

The mean eosinophil count was higher in the males than females in both NSAIDs users and the controls. Table 3 compared the eosinophil count of NSAIDs users and the healthy controls. The eosinophil count was positively associated with the age and BMI but had an inverse relationship with the GFR in both the NSAIDs users and controls.

Among the NSAIDs users, there was a positive relationship between the eosinophil count and the doses of each drug. Table 4 shows the relationship between the eosinophil count and the various doses of single NSAIDs used by participants. The mean eosinophil count was highest in Ketoprofen and Ibuprofen and it was least with Aceclofenac. The difference between the smaller and the larger doses of NSAIDs, in terms of mean eosinophil count, was statistically lower in Ketoprofen $(\mathrm{P}=1.0)$ and Ibuprofen $(\mathrm{P}=0.8)$ compared to Aceclofenac $(\mathrm{P}=0.5)$ and Meloxicam $(\mathrm{P}=0.4)$. The mean eosinophil of single NSAIDs users was $156.15 \pm 23.61$ compared to $176.46 \pm 28.16$ for those that used two or more NSAIDs. The difference was statistically significant, $\mathrm{P}=0.04$.

As the BMI of NSAIDs users increased, the eosinophil count increased and the difference was statistically significant, $\mathrm{P}=0.04$. There was a direct relationship between the eosinophil count and the duration of NSAIDs use, $\mathrm{P}=0.01$. The determinants of eosinophil count amongst the NSAIDs users are shown in Table 5. The eosinophil count increased with the age of participants, and the systolic and diastolic blood pressure but the differences were not statistically significant, $\mathrm{P}=1.6$, and $\mathrm{P}=0.05$ and $\mathrm{P}=0.9$ respectively.

\section{Discussion}

Our series found a non-statistically significant increase in eosinophil count in frequent NSAIDs users compared to a healthy population. The degree of this increase was directly proportional to the duration of NSAIDs use. The increase was also more in males than females as it was for participants who were overweight or obese compared to those who were underweight. The increase in eosinophil count was more in the older age group than in the young. The increase in eosinophil count in NSAIDs users mirrors findings by Satoh et al. [8] and Kataoka et al. [20] who reported in separate studies that NSAIDs use is associated with elevated eosinophil count but they noted that the only drug associated with the hypereosinophilic syndrome was Indomethacin, which unlike other NSAIDs, 
is a potent agonist of the $\mathrm{PGD}_{2}$ receptor, chemoattractant receptor-homologous molecule expressed on $\mathrm{T}$ helper type 2 cells $\left(\mathrm{CRTH}_{2}\right)$. The decreased eosinophil response to $\mathrm{PGD}_{2}$ was associated with reduced priming of the chemotactic actions of eosinophil as a result of downregulation of $\mathrm{CRTH}_{2}$ cell surface expression [10]. We, therefore, infer that the low incidence of eosinophilia was secondary to the non-availability of Indomethacin for use by participants.

Table 2. Laboratory results of participants.

\begin{tabular}{|c|c|c|c|c|}
\hline \multirow{3}{*}{ Variables } & NSAIDs users & Controls & \multirow{3}{*}{ t-test } & \multirow{3}{*}{$\mathrm{P}$-value } \\
\hline & $\mathrm{N}=100(\%)$ & $\mathrm{N}=100(\%)$ & & \\
\hline & Mean \pm SD & Mean \pm SD & & \\
\hline Mean Total WBC, $\times 10^{6} / L$ & $5.2 \pm 2.3$ & $5.1 \pm 1.7$ & 0.6 & 0.4 \\
\hline Mean Eosinophils, $\times 10^{6} / L$ & $164.3 \pm 516$ & $135.6 \pm 53.4$ & 0.8 & 0.4 \\
\hline Mean Hematocrit, \% & $36.8 \pm 7.3$ & $40.2 \pm 11.5$ & 1.7 & 0.02 \\
\hline Mean Platelet count $\times 10^{9} / L$ & $386.5 \pm 44.7$ & $349.8 \pm 56.2$ & 1.1 & 0.04 \\
\hline Mean FBS, mmol & $4.8 \pm 1.4$ & $4.9 \pm 1.2$ & 0.1 & 0.4 \\
\hline Mean Creatinine, umol/l & $99.6 \pm 13.3$ & $69.5 \pm 9.1$ & 5.7 & $<0.001$ \\
\hline Mean eGFR, $\mathrm{ml} / \mathrm{min}$ & $87.8 \pm 3.1$ & $115.0 \pm 2.7$ & 9.4 & $<0.001$ \\
\hline
\end{tabular}

NSAIDs-non-steroidal anti-inflammatory drugs, SD-standard deviation, WBC-white cell count, FBS-fasting blood sugar, eGFR-estimated glomerular filtration rate.

Table 3. Comparison between the Eosinophil counts of NSAIDs users and controls.

\begin{tabular}{|c|c|c|c|c|c|}
\hline \multirow{2}{*}{\multicolumn{2}{|c|}{ Variables }} & NSAIDs users & Controls & \multirow[b]{2}{*}{ t-test } & \multirow[b]{2}{*}{ P-value } \\
\hline & & Eosinophil $\left(\times 10^{6}\right)$ & Eosinophil $\left(\times 10^{6}\right)$ & & \\
\hline \multicolumn{2}{|l|}{ Eosinophil count, $10^{6} / L$} & $164.3 \pm 51.6$ & $136.9 \pm 53.4$ & 0.8 & 0.4 \\
\hline \multirow[t]{2}{*}{ Sex: } & Males & $191.1 \pm 22.7$ & $146.0 \pm 30.2$ & 1.2 & 0.2 \\
\hline & Females & $137.6 \pm 20.9$ & $128.2 \pm 29.6$ & 0.2 & 0.8 \\
\hline \multirow[t]{3}{*}{ Age, years } & $20-39$ & $138.6 \pm 14.8$ & $122.6 \pm 33.9$ & 0.1 & 0.9 \\
\hline & $40-59$ & $163.6 \pm 17.3$ & $133.6 \pm 18.6$ & 1.4 & 0.1 \\
\hline & $>60$ & $191.4 \pm 29.5$ & $153.4 \pm 36.2$ & 0.4 & 0.6 \\
\hline \multirow[t]{3}{*}{ BMI, $\mathrm{kg} / \mathrm{m}^{2}$} & $<19.5$ & $150.3 \pm 16.3$ & $128.8 \pm 42.2$ & 1.7 & 0.07 \\
\hline & $19.5-24.9$ & $154.7 \pm 21.4$ & $125.7 \pm 11.9$ & 1.5 & 0.06 \\
\hline & $>25.0$ & $188.2 \pm 24.5$ & $157.6 \pm 23.2$ & 1.5 & 0.05 \\
\hline \multirow[t]{2}{*}{ eGFR, $\mathrm{ml} / \mathrm{min}$} & $<60$ & $183.4 \pm 19.9$ & $144.0 \pm 21.4$ & 0.2 & 0.8 \\
\hline & $>60$ & $146.1 \pm 18.6$ & $129.1 \pm 16.6$ & 1.1 & 0.2 \\
\hline
\end{tabular}

NSAIDs-non-steroidal anti-inflammatory drugs, eGFR = estimated glomerular filtration rate, CKD-EPI = chronic kidney disease epidemiology collaboration. 
Table 4. Relationship between eosinophil counts and various doses of each NSAID.

\begin{tabular}{|c|c|c|c|c|}
\hline \multirow{2}{*}{ Variables } & \multirow{2}{*}{ Frequency (\%) } & n Eosinophil $\left(\times 10^{6}\right)$ & \multirow{2}{*}{ t-test } & \multirow{2}{*}{ P-value } \\
\hline & & Mean \pm SD & & \\
\hline \multicolumn{5}{|c|}{ Aceclofenac, $m g$} \\
\hline 100 & $1(1)$ & $123.2 \pm 22.8$ & 0.45 & 0.5 \\
\hline 200 & $2(2)$ & $131.2 \pm 18.2$ & & \\
\hline \multicolumn{5}{|c|}{ Diclofenac, $m g$} \\
\hline 50 & $10(10)$ & $137.3 \pm 31.5$ & 0.31 & 0.7 \\
\hline 100 & $14(14)$ & $142.1 \pm 44.3$ & & \\
\hline \multicolumn{5}{|c|}{ Ibuprofen, $m g$} \\
\hline 600 & $4(4)$ & $172.4 \pm 33.8$ & 0.23 & 0.8 \\
\hline 1200 & $2(2)$ & $179.5 \pm 40.3$ & & \\
\hline \multicolumn{5}{|c|}{ Ketoprofen, $m g$} \\
\hline 100 & $4(4)$ & $178.3 \pm 58.7$ & 0.11 & 1.0 \\
\hline 200 & $6(6)$ & $179.9 \pm 66.5$ & & \\
\hline \multicolumn{5}{|c|}{ Meloxicam, $m g$} \\
\hline 7.5 & $5(5)$ & $154.4 \pm 25.8$ & 0.52 & 0.4 \\
\hline 15 & $11(11)$ & $163.2 \pm 31.8$ & & \\
\hline
\end{tabular}

NSAID $=$ non-steroidal anti-inflammatory drug.

Table 5. Determinants of eosinophil count among frequent NSAIDs users.

\begin{tabular}{|c|c|c|c|c|c|}
\hline \multicolumn{2}{|l|}{ Variables } & \multirow{2}{*}{$\begin{array}{l}\text { Frequency } \\
\mathrm{N}=100(\%)\end{array}$} & \multirow{2}{*}{$\begin{array}{c}\text { Mean Eosinophil }\left(\times 10^{6}\right) \\
\text { Mean } \pm \text { SD }\end{array}$} & \multirow[t]{2}{*}{ t-test } & \multirow[t]{2}{*}{ P-value } \\
\hline & & & & & \\
\hline \multirow[t]{2}{*}{ Gender } & Males & $49(49)$ & $191.1 \pm 22.7$ & 2.16 & 0.05 \\
\hline & Females & $51(51)$ & $137.6 \pm 20.9$ & & \\
\hline \multirow[t]{3}{*}{ Age, years } & $18-39$ & $32(32)$ & $138.6 \pm 14.8$ & 0.42 & 1.6 \\
\hline & $40-59$ & $53(53)$ & $163.6 \pm 17.3$ & & \\
\hline & $>60$ & $15(15)$ & $191.4 \pm 29.5$ & & \\
\hline \multirow[t]{2}{*}{ NSAIDs types } & 1 & $59(59)$ & $163.7 \pm 130.8$ & 0.25 & 1.9 \\
\hline & $>2$ & $41(41)$ & $166.0 \pm 25.6$ & & \\
\hline \multirow[t]{4}{*}{ Duration, months } & $0-6$ & $23(23)$ & $142.6 \pm 36.1$ & 3.02 & 0.01 \\
\hline & $7-12$ & $36(36)$ & $149.1 \pm 32.6$ & & \\
\hline & $13-60$ & $35(35)$ & $184.5 \pm 42.9$ & & \\
\hline & $>60$ & $6(6)$ & $222.8 \pm 32.9$ & & \\
\hline \multirow[t]{3}{*}{ BMI, $\mathrm{kg} / \mathrm{m}^{2}$} & $<19.5$ & $17(17)$ & $150.3 \pm 16.3$ & 2.42 & 0.04 \\
\hline & $19.5-24.9$ & $49(49)$ & $154.7 \pm 21.4$ & & \\
\hline & $>25.0$ & $34(34)$ & $188.2 \pm 24.5$ & & \\
\hline \multirow[t]{2}{*}{ Systolic BP, $\mathrm{mmHg}$} & $<120$ & $29(29)$ & $148.6 \pm 77.4$ & 2.32 & 0.05 \\
\hline & $120-139$ & $71(71)$ & $180.8 \pm 29.4$ & & \\
\hline \multirow[t]{2}{*}{ Diastolic BP, $m m H g$} & $<80$ & $36(36))$ & $159.7 \pm 41.9$ & 0.8 & 0.9 \\
\hline & $80-89$ & $64(64)$ & $169.2 \pm 41.9$ & & \\
\hline
\end{tabular}

NSAIDs-non-steroidal anti-inflammatory drugs, BMI-body mass index, BP-blood pressure. 
The mean age of the NSAIDs users was less than what other studies found in Nigeria, Iran and in the United States [3] [5] [6]. This difference could be attributed to the fact that chronic diseases, commonly found in the elderly, like hypertension and diabetes, were excluded in this study. One would have expected more women participation in the study considering that the fact that females are more commonly associated with rheumatologic disorders, coupled with cyclic pains experienced by women during their menstrual circle [1]. The higher mean BMI in NSAIDs users than in healthy controls is similar to findings by Schwartz et al. who found an increased incidence of acute kidney dysfunction in NSAIDs users with attendant fluid retention and weight gain [21]. The higher eosinophil count in males mirrors findings by Pardo et al. [22] and Tariq et al. [23] who found this pattern more common in participants without kidney disease. Ogbogu et al. [11] and Loules et al. [24] separately reported higher eosinophil count in males and attributed it to the presence of the pre-mRNA 3 '-end-processing factor FIP1-platelet derived growth factor receptor A (FIP1L1-PDGFRA) fusion genes in males. The authors reported that when eosinophils are pretreated with Indomethacin, eosinophilic migration towards PGD2 was suppressed [24].

We found higher eosinophil count in the older age group and this agrees with Praga et al. [25] who attributed this to the higher incidence of eosinophilia associated with acute interstitial nephritis in advancing age. There was a positive relationship between eosinophil count and body size and this mirrors findings by Amani et al. [26]. The findings however disagree with findings by Berair et al. [27] who found no relationship between eosinophilia and obesity. Obesity is associated with elevated triglycerides, total cholesterol and glycated hemoglobin as well as reductions in high-density lipoprotein [26].

Even though hypertensives were excluded from our study, we found that within normal ranged blood pressures, eosinophil counts were positively correlated with blood pressure. Hypertension and obesity are chronic conditions associated with elevated cytokine release and oxidative stress which are associated with elevated eosinophil count [28]. Masenger et al. [29] on behalf of the American Heart Asssociation (AHA) reported the association between hypertension and eosinophilia. Hypertension is associated with increased infiltration of macrophages into the kidneys, increasing victims' risk for chronic kidney disease (CKD) with increases commonly found in IL-6 and IL-17 with concurrent reductions in the anti-inflammatory IL-10 [30] Madhur et al. [31] also reported angiotensin II induced hypertension associated with elevated IL-17, further emphasizing the relationship between elevated eosinophil and IL-17.

Elevated eosinophil count was positively related with the platelet count in our study and this mirrors findings by Shah et al. [32] The association between eosinophil and platelets is said to be symbiotic, as eosinophil activates platelets in a dual, indeed bimodal faction as, eosinophil derived inflammatory mediators stimulate platelets while some eosinophil derived mediators are reported to inhibit platelet activities. The findings of eosinophil in mural thrombus associated 
with acute coronary events like myocardial infarction, a condition associated with platelet aggregation further confirms the symbiotic association between the two [33]. The negative relationship between eosinophil count and the hematocrit in this study is in agreement with findings by Sweidan et al. [18] who reported a case of autoimmune hemolytic anemia with Ibuprofen use. The pro-inflammatory features of eosinophils stimulate hemolysis, from disruption in membrane proteins, leading to altered cell cellular adhesion, increased permeability and osmotic fragility.

The finding of an inverse relationship between eosinophils and the blood glucose level in this study agrees with findings by Zhu et al. [34] and Ment et al. [35]. The suppressive effect of glucocorticoids on the eosinophil with background leukocytosis could be multifactorial, one mechanism being increased apoptosis induced by reductions in IL-5, an anti-apoptotic agent that stimulates eosinophil maturation and prevent its destruction [36]. The inverse relationship between eosinophil and $\mathrm{HbAic}$, and also with, the severity of Cushing syndrome is further explained by the interaction between glucocorticoids and eosinophils. The higher eosinophil count in NSAIDs users compared to healthy controls could be attributed to the widely reported findings that the eosinophil counts are elevated in kidney disease [37]. Inflammatory mediators are commonly elevated in $\mathrm{KD}$, particularly chronic kidney disease (CKD), and these stimulate eosinophil release. The infiltration of the kidneys and the perivascular spaces by macrophages and other inflammatory cytokines, can cause renal dysfunction or cause acute depression of kidney function in patients with background CKD. It therefore becomes apparent that a "cause and effect" relationship exists between elevated eosinophils count and kidney disease [38].

Even though no significant difference in eosinophil count was found between the different doses of each of the commonly used NSAIDs, it is worth noting that higher doses were associated with higher eosinophil levels. We infer that this finding strongly suggests that the kidney function decline in NSAIDs users is more dependent on the drug type than the drug dosage. This is more so considering the fact that Ibuprofen, probably the most nephrotoxic of the NSAIDs used, showed the least difference between the two dosages that were compared [39]. We found a positive relationship between the length of drug exposure and the eosinophil count. In acute inflammatory conditions, eosinophils stimulate the release of acute inflammatory mediators like IL-1, TNF- $\alpha$, IL-6, platelet-activating factors (PAF) and various adhesion molecules leading to tissue injury associated with increased extravasation of fluid and the release of pro-apoptotic agents which reduces peripheral platelet count [40]. In chronic inflammatory conditions, eosinophils cause the release of transforming growth factor $\beta$ (TGF $\beta$ ), IL-4 and IL-13. These profibrotic mediators cause tissue fibrosis and dysfunction. [41]. This pattern is also supported by findings of progressive decline in kidney function in acute interstitial nephritis progressing to chronic interstitial nephritis (CKD) in NSAIDs users who have used the drugs for more than a month. [21]. The increase in echogenicity, tubular atrophy, tu- 
bular wall dilatation with papillary calcification seen in analgesic nephropathy is morphologically represented in the small, indented calcified kidneys seen in this condition [42].

The usefulness of NSAIDs in the control of pain needed to be balanced with various consequences of their use including the attendant risk of kidney dysfunction, induction of the inflammatory cascade, cytokine release and tissue damage, fibrosis and loss of function. These changes would therefore be more in the elderly, obesity and people with background kidney disease. It becomes imperative therefore that these population groups should be given lower doses of these drugs or given other pain suppressing agents as a way of avoiding/minimizing the tissue damage associated with NSAIDs.

We acknowledge some limitations encountered in our study. Some allergic conditions could have been present which participants could have misunderstood as other health conditions. The reliability of the screening process is dependent more on the sensitivity and correctness of the stool examination findings. The determination of the eosinophil count could also be operator-dependent.

\section{Conclusion}

The use of NSAIDs is very common worldwide, more so, in low-income nations. The incidence of eosinophilia was $4 \%$ in NSAIDs users. NSAIDs use was associated with elevations in BMI, blood pressure within normal, eosinophil count, platelet count and serum creatinine as it was associated with reductions in the hematocrit, eGFR and blood glucose. Eosinophilia was common in males, advancing age, kidney dysfunction and in combined and prolonged NSAIDs use. The eosinophil count was also positively related to the dose of an NSAID. The study showed that higher eosinophil count was associated with inflammatory conditions and conditions with increased risk for inflammation hence it was associated with advancing age and kidney dysfunction. There is therefore need to minimize eosinophilia and its attendant consequences by preventing and/or treating inflammatory conditions.

\section{Acknowledgements}

We appreciate the support of the clinical and non-clinical staffs of the hematology unit, Federal Medical Centre, Abeokuta.

\section{Conflicts of Interest}

The authors declare no conflicts of interest regarding the publication of this paper.

\section{References}

[1] De Broe, M.E. and Elseviers, M.M. (2009) Over-the-Counter Analgesic Use. Journal of the American Society of Nephrology, 20, 2098-2103. 
https://doi.org/10.1681/ASN.2008101097

[2] Agaba, E.L., Agaba, P.A. and Wigwe, C.M. (2004) Use and Abuse of Analgesic in Nigeria. Nigerian Journal of Medicine, 13, 379-382.

[3] Hamzat, T.K. and Ajala, A.O. (2010) Interaction between Anti-Hypertensives and Non-Steroidal Anti-Inflammatory Drugs: Implication in Management of Osteoarthritis and Opinion on a Compromise Therapy. Internet Journal of Medical Update, $\mathbf{5}$, 42-47. https://doi.org/10.4314/ijmu.v5i1.49293

[4] Zhou, Y., Boudreau, D.M. and Freedman, A.N. (2014) Trends in the Use of Aspirin and Nonsteroidal Anti-Inflammatory Drugs in the General U.S Population. Pharmacoepidemiology and Drug Safety, 23, 43-50.

[5] Zeinali, M., Tabeshpour, J., Maziar, S.V., Taherzadeh, Z., Zirak, M.R., Sent, D., et al. (2017) Prescription Pattern Analysis of Nonsteroidal Anti-inflammatory Drugs in the Northeastern Iranian Population. Journal of Research in Pharmacy Practice, 6, 206-210. https://doi.org/10.4103/jrpp.JRPP $17 \quad 45$

[6] Steinke, J.W., Negri, J., Liu, L., Payne, S.C. and Borish, L. (2014) Aspirin Activation of Eosinophils and Mast Cells: Implications in the Pathogenesis of Aspirin-Exacerbated Respiratory Diseases. The Journal of Immunology, 193, 41-47.

[7] Kim, G.-H. (2008) Renal Effects of Prostaglandins and Cyclooxygenase-2 Inhibitors. Electrolyte Blood Press, 6, 35-41. https://doi.org/10.5049/EBP.2008.6.1.35

[8] Satoh, T., Shimura, C., Miyagishi, C. and Yokozeki, H. (2010) Indomethacin-Induced Reduction in CRTH2 in Eosinophilic Pustular Folliculitis (Ofuji's Disease): A Proposed Mechanism of Action. Acta Dermato Venereologica, 90, 18-22. https://doi.org/10.2340/00015555-0759

[9] Ullmann, N., Bossley, C.J., Fleming, L., Silvestri, M., Bush, A. and Saglani, S. (2013) Blood Eosinophil Counts Rarely Reflect Airway Eosinophilia in Children with Severe Asthma. Allergy, 68, 402-406.

[10] Pettipher, R. and Hansel, T.T. (2008) Antagonist of the Prostaglandin D2 Receptor CRTH2. Drug News \& Perspectives, 6, 317-322.

https://doi.org/10.1358/dnp.2008.21.6.1246831

[11] Ogbogu, P.U., Rossing, D.R. and Horne, M.K. (2007) Cardiovascular Manifestations of Hypereosinophilic Syndromes. Immunology and Allergy Clinics of North America, 27, 457-475. https://doi.org/10.1016/j.iac.2007.07.001

[12] Siroux, V., Curt, F., Oryszczyn, M.P., Maccario, J. and Kauffmann, F. (2004) Role of Gender and Hormone-Related Events on IgE, Atopy, and Eosinophils in the Epidemiological Study on the Genetics and Environment of Asthma, Bronchial Hyperresponsiveness and Atopy. The Journal of Allergy and Clinical Immunology, 114, 491-498. https://doi.org/10.1016/j.jaci.2004.05.027

[13] Wang, X., Mensinga, T.T., Schouten, J.P., Rijcken, B. and Weiss, S.T. (2004) Determinants of Maximally Attained Level of Pulmonary Function. American Journal of Respiratory and Critical Care Medicine, 169, 941-949.

https://doi.org/10.1164/rccm.2201011

[14] Paulose-Ram, R., Hirsch, R., Dillon, C. and Gu, Q. (2005) Frequent Monthly Use of Selected Non-Prescription and Prescription Non-Narcotic Analgesics among U.S. Adults. Pharmacoepidemiology and Drug Safety, 14, 257-266.

[15] Nutman, T.B. (2007) Evaluation and Differential Diagnosis of Marked, Persistent eosinophIlia. Immunology and Allergy Clinics of North America, 27, 529-549. https://doi.org/10.1016/j.iac.2007.07.008

[16] Simon, D. and Simon, H.U. (2007) Eosinophilic Disorders. Journal of Allergy and 
Clinical Immunology, 119, 1291-1300. https://doi.org/10.1016/j.jaci.2007.02.010

[17] Uduagbamen, P.K., Salako, B.L., Hamzat, M.A., Kadiri, S. and Arogundade, F.A. (2020) Kidney Function in Frequent Users of Non-Steroidal Anti-Inflammatory Drugs (NSAIDs). Open Journal of Internal Medicine, 10, 69-82. https://doi.org/10.4236/ojim.2020.101007

[18] Sweidan, A.J., Brys, A.K., Sohn, D.D. and Sheth, M.R. (2015) Diagnostic and Therapeutic Considerations in Idiopathic Hypereosinophilia with Warm Autoimmune Hemolytic Anemia. Journal of Blood Medicine, 6, 257-260. https://doi.org/10.2147/JBM.S90078

[19] Araoye, M.O. (2003) Sample Size Determination. In: Margaret, O.A., Ed., Research Methodology with Statistics for Health and Social Sciences, Nathadex Publishers, Ilorin, 115-119.

[20] Kataoka, N., Satoh, T., Hirai, A., Saeki, K. and Yokozeki, H. (2013) Indomethacin Inhibits Eosinophil Migration to Prostaglandin $\mathrm{D}_{2}$ : Therapeutic Potential of CRTH2 Desensitization for Eosinophilic Pustular Folliculitis. Immunology, 140, 78-86.

[21] Schwarz, A., Krause, P.H., Kunzendrof, V., Keller, F. and Distler, A. (2000) The Outcome of Acute Interestial Nephritis: Risk Factors for the Transition from Acute to Chronic Interstistial Nephritis. Clinical Nephrology, 54, 179-190.

[22] Pardo, J., Carranza, C., Muro, A., Angel-Moreno, A., Martín, A.M., Martín, T., et al. (2006) Helminth-Related Eosinophilia in African Immigrants, Gran Canaria. Emerging Infectious Diseases, 12, 1587-1589.

https://doi.org/10.3201/eid1210.060102

[23] Tariq, A., Okamato, K., Tariq, A., et al. (2020) Eosinophilia and Risk of Incident End Stage Kidney Disease. BMC Nephrology, 21, Article No.: 14. https://doi.org/10.1186/s12882-020-1685-3

[24] Loules, G., Kalala, F., Giannakoulas, N., Papadakis, E., Matsouka, P. and Speletas, M. (2009) FIP1L1-PDGFRA Molecular Analysis in the Differential Diagnosis of Eosinophilia. BMC Hematology, 9, Article No.: 1. https://doi.org/10.1186/1471-2326-9-1

[25] Praga, M., Sevillano, A., Auñón, P. and González, E. (2015) Changes in the Aetiology, Clinical Presentation and Management of Acute Interstitial Nephritis, an Increasingly Common Cause of Acute Kidney Injury. Nephrology Dialysis Transplantation, 30, 1472-1479. https://doi.org/10.1093/ndt/gfu326

[26] Amini, M., Bashirova, D., Prins, B.P. and Corpeleijn, E. Bruinenberg, M., Franke, L., Harst, P., Navis, G., Wolffenbuttel, B.H.R., Stolk, R.P., et al. (2016) Eosinophil Count Is a Common Factor for Complex Metabolic and Pulmonary Traits and Diseases: The LifeLines Cohort Study. PLos ONE, 11, e0168480.

https://doi.org/10.1371/journal.pone.0168480

[27] Berair, R., Mistry, V., Singapuri, A., Gonem, S., Newby, C., Siddiqui, S., et al. (2014) Association between Body Mass Index (BMI) and Markers of Eosinophilic Inflammation in Asthma. European Respiratory Journal, 44, 3870.

[28] Nguyen, H., Chiasson, V.L., Chatterjee, P., Kopriva, S.E., Young, K.J. and Mitchell, B.M. (2013) Interleukin-17 Causes Rho-Kinase-Mediated Endothelial Dysfunction and Hypertension. Cardiovascular Research, 97, 696-704. https://doi.org/10.1093/cvr/cvs422

[29] Masenga, S.K., Elijovich, F., Hamooya, B.M., Nzala, S.G., Heimburger, D.C., et al. (2020) Elevated Eosinophils as a Feature of Inflammation Associated with Hypertension in Virally Suppressed People Living with HIV. Journal of the American Heart Association, 9, No. 4. https://doi.org/10.1161/JAHA.118.011450 
[30] Chiasson, V.L., Talreja, D., Young, K.J., Chatterjee, P., Banes-Berceli, A.K. and Mitchell, B.M. (2011) FK506 Binding Protein 12 Deficiency in Endothelial and Hematopoietic Cells Decreases Regulatory T Cells and Causes Hypertension. Hypertension, 57, 1167-1175. https://doi.org/10.1161/HYPERTENSIONAHA.110.162917

[31] Madhur, M.S., Lob, H.E., McCann, L.A., Iwakura, Y., Blinder, Y., Guzik, T.J. and Harrison, D.G. (2010) Interleukin 17 Promotes Angiotensin II-Induced Hypertension and Vascular Dysfunction. Hypertension, 55, 500-507. https://doi.org/10.1161/HYPERTENSIONAHA.109.145094

[32] Shah, S.A., Page, C.P. and Pitchford, S.C. (2017) Platelet-Eosinophil Interactions as a Potential Therapeutic Target in Allergic Inflammation and Asthma. Frontiers in Medicines, 4, 129. https://doi.org/10.3389/fmed.2017.00129

[33] Salanitri, G.C. (2005) Endomyocardial Fibrosis and Intracardiac Thrombus Occurring in Idiopathic Hypereosinophilic Syndrome. American Journal of Roentgenology, 184, 1432-1433. https://doi.org/10.2214/ajr.184.5.01841432

[34] Zhu, L., Su, T., Xu, M., Xu, Y., Li, M., Wang, T., et al. (2013) Eosinophil Inversely Associates with Type 2 Diabetes and Insulin Resistance in Chinese Adults. PLoS ONE, 8, e67613. https://doi.org/10.1371/journal.pone.0067613

[35] Meng, W., Zhang, C., Zhang, Q., Song, X., Lin, H., Zhang, D., et al. (2012) Association between Leukocyte and Metabolic Syndrome in Urban Han Chinese: A Longitudinal Cohort Study. PLOS ONE, 7, e49875.

https://doi.org/10.1371/journal.pone.0049875

[36] Huang, Z.S., Chien, K.L., Yang, C.Y., Tsai, K.S. and Wang, C.H. (2001) Peripheral Differential Leukocyte Counts in Humans Vary with Hyperlipidemia, Smoking, and Body Mass Index. Lipids, 36, 237-245.

[37] Li, N., van der Sijde, M.R., LifeLines Cohort Study Group, Bakker, S.J., Dullaart, R.P., van der Harst, P., et al. (2014) Pleiotropic Effects of Lipid Genes on Plasma Glucose, HbA1c, and HOMA-IR Levels. Diabetes, 63, 3149-3158. https://doi.org/10.2337/db13-1800

[38] Diskin, C.J., Stokes, T.J., Dansby, L.M., Radcliff, L. and Carter, T.B. (2011) The Prevalence and Meaning of Eosinophilia in Renal Diseases on a Nephrology Consultation Service. Nephrology Dialysis Transplantation, 26, 2549-2558. https://doi.org/10.1093/ndt/gfq745

[39] Oda, E. (2014) Longitudinal Associations between Lymphocyte Count and LDL Cholesterol in a Health Screening Population. Journal of Clinical \& Translational Endocrinology, 1, 49-53. https://doi.org/10.1016/j.jcte.2014.05.001

[40] Aceves, S.S. and Broide, D.H. (2008) Airway Fibrosis and Angiogenesis Due to Eosinophil Trafficking in Chronic Asthma. Current Molecular Medicine, 8, 350-358. https://doi.org/10.2174/156652408785161023

[41] Postma, D.S. (2007) Gender Differences in Asthma Development and Progression. Gender Medicine, 4, S133-S146. https://doi.org/10.1016/S1550-8579(07)80054-4

[42] Vadivel, N., Trikudanathan, S. and Singh, A.K. (2007) Analgesic Nephropathy. Kidney International ( The Renal Consult), 72, 517-520. https://doi.org/10.1038/sj.ki.5002251 